\title{
The effect of an electronic health record system on nursing staff time in a nursing home: a longitudinal cohort study
}

\author{
Esther Munyisia ${ }^{1}$, Ping $\mathrm{Yu}^{2}$, David \\ Hailey $^{2}$
}

1. Illawarra Shoalhaven Local Health District, New South Wales Health,Australia

2. School of Information Systems and Technology, The University of Wollongong, Australia

\section{RESEARCH}

Please cite this paper as: Munyisia E, Yu P, Hailey D. The effect of an electronic health record system on nursing staff time in a nursing home: a longitudinal study.
AMJ
2014,
7,
7,
$285-293$.

http://doi.org/10.21767/AMJ.2014.2072

\section{Corresponding Author:}

Ping Yu

School of Information Systems and Technology,

The University of Wollongong, Australia

Email: ping@uow.edu.au

\section{ABSTRACT}

\section{Background}

Nursing homes are increasingly introducing electronic health record (EHR) systems into nursing practice; however, there is limited evidence about the effect of these systems on nursing staff time.

\section{Aims}

To investigate the effect of introducing an EHR system on time spent on activities by nursing staff in a nursing home.

\section{Method}

An observational work sampling study was undertaken with nursing staff between 2009 and 2011 at two months before, and at 3, 6, 12, and 23 months after implementation of an EHR system at an Australian nursing home. An observer used pre-determined tasks to record activities of the nursing staff at nine-minute intervals.

\section{Results}

There was no significant change in registered nurses and endorsed enrolled nurses' time on most activities after implementation. Personal carers' time on oral-communication reduced, and time on documentation increased at most measurement periods in the first 12 months after implementation. At 23 months, time on these activities had returned to pre-implementation levels. Nursing staff time on direct care remained stable after implementation. No considerable change was observed in time spent on other activities after implementation.

\section{Conclusion}

Findings suggest that successful introduction of an EHR system in a nursing home may not interfere with nursing staff time on direct care duties. However, there is scope for improving the support provided by EHR systems through incorporation of functions to support collaborative nursing care.

\section{Key Words}

Activity, electronic health record, HER, impact, nurse, nursing home

\section{What this study adds:}

\section{What is known about this topic?}

Although the introduction of an EHR system in a nursing home can improve documentation practice for nursing staff, maintaining this positive change can be a challenge.

\section{What new information is offered in this study?}

To effectively support collaborative nursing care in a nursing home, it is important for designers of EHR systems to incorporate the necessary functions into the system to support point-of-care documentation and realtime exchange of care information.

3. What are the implications for research, policy, or practice?

The introduction of an electronic documentation system in a nursing home does not necessarily interfere with the caring duty of the nursing staff.

\section{Background}

The electronic health record (EHR) is increasingly becoming a necessary technology in healthcare settings. For aged care services, this technology has the potential to improve efficiency and management of nursing records 
and safety of patients, ${ }^{1-2}$ thereby improving the quality of care provided to older people in nursing homes. To benefit from the introduction of EHR, nursing staff have been urged and encouraged to embrace EHR systems with the promise that such systems will reduce documentation, increase direct care time and facilitate delivery of high quality care. ${ }^{3}$

A number of studies assessing the effects of these systems on nursing work have been conducted in hospitals and their focus has been mainly on time spent on activities by nursing staff. ${ }^{4-7}$ For example, six months after the implementation of an EHR system in an intensive care unit of a surgical ward, Wong et al. found that nursing staff spent more time on direct care (i.e. patient examination), indirect care (i.e. report and exchange of patient information), administration (i.e. staff meetings), and housekeeping activities (i.e. room set-up) compared with the time spent on these activities using a paper-based system. Their time on documentation duties (i.e. recording of hourly output) decreased significantly after implementation. ${ }^{7}$ Little attempt, however, has been made to assess the effect of an EHR system on the work of nursing staff in a nursing home. Thus, there is limited understanding about how these systems may affect the time nursing staff spend on activities in this setting.

In our recent study, we found that use of an EHR system in a nursing home may not necessarily reduce the amount of time nursing staff spend on documentation. ${ }^{8}$ In another study, interviews with nursing staff revealed that an EHR system reduced the time on access to residents' records and documentation. These staff had mixed views about the effect of the EHR system on their time on direct care work. Some staff felt that their time had increased; others thought it had reduced, while others believed that there was no difference between the time on direct care work when using a computerised system versus manual (paper-based) approaches. ${ }^{9}$ Thus, there is no conclusive evidence about the effects of an EHR system on time spent on activities by nursing staff in this setting.

This information is useful in addressing one major barrier for the implementation of EHR systems in nursing homes, that is, uncertainty about the effect of such systems on nursing staff's work practices. ${ }^{10}$ This knowledge is needed by management of nursing homes not only to validate positive outcomes of investment in such systems, but also to guide decisions on their effective implementation.

We carried out a 25-month longitudinal study to investigate the effect of the introduction of an EHR system on time spent on all activities by nursing staff in a high care house of a nursing home. In the Australian aged care system, older people in this care setting fully depend on nursing staff to accomplish their physical activities of daily living (ADL) such as meals, showering and toileting. ${ }^{11}$

\section{Method}

Setting

This study was conducted between 2009 and 2011. The work is part of a larger multi-method study evaluating the impact of introducing EHRs in nursing homes. Publications in this area have been focused on documentation efficiency of the EHR system in the nursing home. ${ }^{8,12}$

The high care house has two nursing stations and one common room for meals and breaks. The house takes care of up to 53 older people at any given time of the year. On a typical morning shift, care is provided by one registered nurse (RN), one endorsed enrolled nurse (EEN), one recreational activity officer (RAO), and 12 personal carers (PCs).

The EHR system implemented at the house was webbased. The system was introduced in May 2009 and contains partial information required for the care of an older person. It supports residents' demographic information, care plans, assessments, incident and accident reports, shift handover reports, forms and charts, documents for funding, and daily care notes, including information on medication changes by doctors. Other information such as medication management, ADLs, recreational activities, and scheduled tasks were recorded and maintained on paper throughout the study. Details of the documentation practice at the house after the implementation of the EHR system have been reported by Munyisia et al. ${ }^{8}$

The EHR system was installed on six desktop computers; four were located at one nursing station for access by the PCs, and the other two at another station mainly for access by the RNs and EENs. All nursing staff received a 30-minute one-on-one training session prior to implementation of the EHR system. New employees learned to use the system from their colleagues with experience using it. Continuous training was provided by the home's information technology support officer or by nursing staff members with more experience using the system in their work.

\section{Participants}

The participants in this study included RNs, EENs, and PCs working on a morning shift $(6.45 \mathrm{am}-3.15 \mathrm{pm})$. This shift was chosen because most care activities at the nursing home were performed during this period and hence, the shift was deemed sufficient in providing the needed sample size for the study. This decision was reached in a 
discussion with the home's residential service manager. This investigation excluded nursing staff working on afternoon and night shifts. Others excluded were doctors, RNs assigned to administrative tasks, nursing staff on orientation, temporary employees from an employment agency, and allied healthcare staff such as physiotherapists.

\section{Roles of the nursing staff}

\section{The RNs and EENs}

The RNs and EENs are the professional nursing staff in Australia's nursing home system. They are responsible for ensuring the smooth running of a work-shift, including supervision of the PCs' activities. They are also responsible for carrying out continuous assessment of each resident's status, and planning, implementing, and evaluating nursing care provided to the residents. ${ }^{13-14}$ In addition, they are required to perform documentation duties for their work shift. The RNs are also fully responsible for the administration of drugs of addiction. $^{15}$

\section{Personal carers}

Personal carers form the largest group of nursing staff in Australian nursing homes. ${ }^{16}$ They provide basic care to the residents; for example, showering and toileting. They also restock supplies and aid the residents in their mobility. In addition, they are responsible for completing their documentation duties in a work shift. Personal carers practice under the direct supervision of an RN or an EEN. ${ }^{13}$

\section{Data collection}

Data was collected on a morning shift at five different measurement periods (Table 1); that is, at two months before the implementation of the EHR system, and then at 3, 6, 12, and 23 months after implementation. These periods represent the various stages of EHR system implementation: preimplementation stage, learning period, system stabilisation, and the period when the system is fully integrated into routine practice. ${ }^{17}$ Each study period lasted for five days (Monday, Tuesday, Wednesday, Saturday, and Sunday).

\section{Study design and procedures}

This study used a work sampling technique with an observational component in data collection. Prior to the first period of study, the observer (ENM) met the nursing staff in their morning shift handover meetings and gave them information sheets about the study to read, understand, and ask any questions. The observer also explained the purpose and method of study to the nursing staff and allayed any fears about the investigation.

This process might have helped the nursing staff to become comfortable with the observer and possibly reduced the Hawthorne effect, leading to an accurate recording of the nursing staff's activities by the observer. After each meeting, the observer invited the nursing staff to participate in the study and they all accepted by signing consent forms.

During data collection, observations were made every nine minutes. The observer followed the same route on each round of observation and recorded all tasks being undertaken by each nursing staff member on a tabular data collection tool using a unique code number allocated to each task. Brief communication between the observer and a caregiver to clarify an activity being undertaken was allowed when necessary. On each day of the study, the observer made 65 to 68 rounds of observations. This methodology was applied at all study periods. Further information about the study procedures can be found in Munyisia et al. ${ }^{8}$

\section{Activities of the nursing staff}

The observer (ENM) used a predetermined set of tasks to identify and record activities of the nursing staff. These tasks and their categories were adapted from previous data collection tools in peer-refereed studies. ${ }^{4,18}$ The procedures of validating the tasks and their categories, including assessment of inter-rater reliability are described elsewhere. ${ }^{19}$ The final instrument contained 48 activities grouped into eight categories. The category of "direct care" included all nursing activities performed in the presence of a resident and/or relative, for example, showering. "Medication management" included all medication-related tasks such as preparation and administration of the medication. "Communication" included all oral-related communication activities such as discussion with allied healthcare workers. "Documentation" included all activities related to paperbased and computer-based documentation tasks such as taking records from the storage place and typing progress notes. "Indirect care" included all activities non-resident specific activities such as identifying correct supplies. "Personal" included all activities unrelated to residents, for example, meal breaks. "In-transit" between tasks included time spent between tasks, and "other nursing duties" included activities not classified anywhereabove.

\section{Data analysis}

Data in MS Excel 2003 spreadsheet were exported to SPSS for analysis using descriptive statistics with 95 per cent confidence interval. Categories with less than five recorded activities at any measurement period during the study were excluded from analysis. The proportion of time spent on documentation activities after implementation includes the time spent on paper-based and computer-based documentation tasks. Comparison 
of the proportion of time spent on activities before and after the implementation of the EHR system was conducted using Pearson's chi-square test. A $p$-value less than 0.05 was considered to be statistically significant. However, due to the multiple comparisons in this study (24 comparisons each for the RNs and PCs, and 20 for the EENs), results were adjusted using the Bonferroni correction.

\section{Results}

A total of 1,925 activities were recorded for the RNs, 1,384 for the EENs and 14,423 for the PCs. In general, 242 nursing staff were observed during the study, 28 RNs, 23 EENs, and 191 PCs. These numbers, however, include double counts of some staff members because the nursing staff observed on each day were either the same people or different people.

\section{The RNs' and EENs' proportion of time on activities before and after the introduction of the EHR system}

Analysis of the proportion of time the RNs and EENs spent on activities before and after the introduction of the EHR system is presented in Table 2 and Table 3, respectively. Compared with the proportion of time spent on activities in the paperbased system, there was no significant change in the RNs' and EENs' proportion of time spent on oral communication after the introduction of the EHR system, except at 23 months postimplementation where the RNs' proportion reduced from 48.4 per cent to 36.2 per cent $(p=0.002)$. No major change was identified in the percentage of time the RNs spent on documentation after implementation, apart from 23 months where the percentage was significantly higher than that recorded in the paper-based system $(p=0.001)$. The EENs' percentage of time on this activity remained stable in the first six months of using the HER system. The percentage reduced significantly at 12 months $(p=0.003)$ and at 23 months $(p=0.001)$ after implementation. No considerable change was noted in their proportion of time on direct care, medication management, personal duties, and in-transit between tasks after the introduction of the EHR system.

\section{The PCs' proportion of time on activities before and after the introduction of the EHR system}

The PCs' proportion of time on activities before and after the introduction of the EHR system is shown in Table 4. There was a significant decrease in the proportion of time spent on oralcommunication at three months $(p<0.001)$, six months $(p=0.001)$ and 12 months $(p<0.001)$ after implementation. At 23 months, the proportion had settled back to the original level evident in the paper-based system. The percentage of time on documentation increased significantly at three months $(p<0.001)$ and six months $(p<0.001)$ into electronic documentation. At 12 and 23 months, respectively, the percentage was not different from that recorded when using the paper-based system. The proportion of time on direct care duties remained stable at all periods after the introduction of the EHR system. There was no significant change in the percentage of time on personal duties after implementation, except at 12 months where the percentage was significantly more than in the paperbased system $(p<0.001)$. Similarly, there was not much change in the proportion of time spent in-transit between tasks after implementation, other than at six months where the proportion increased significantly compared with the value recorded in the pre-implementation period $(p<0.001)$. No significant change was noted in the percentage of time on indirect care duties after implementation.

\section{Discussion}

The RNs' and EENs' proportion of time on almost all activities remained unchanged after the introduction of the EHR system. This finding may in part be associated with these staff members' responsibilities in the workplace including documentation. After implementation, their major documentation duties on the computer included developing and updating the residents' care plans, assessment forms, and preparation of documents for funding. To complete these tasks, they relied on care information entered into computers by the PCs. This information was located in various sections of the HER system and thus, they required searching through the system to find the information. The RNs and EENs also needed to attend to several other duties as the professional nursing staff for a work shift. In addition to their responsibilities of planning, implementing, and evaluating nursing care, they were responsible for supervising the PCs, attending to administrative duties, and communicating with outside healthcare providers such as general practitioners and allied health professionals. ${ }^{14,15}$ Overall, RNs and EENs have the obligation to maintain the normal running of aged care services.

The multi-dimensional nature of practice and busy schedule may have left little room for the RNs and EENs to effectively attend to their documentation, which could possibly lead to changes in their routine work. Indeed, they were often seen remaining in their office at the end of a shift (3.15pm) to complete their documentation tasks on the computer. This after-hour documentation, however, was not captured in our observations as it was conducted outside the timeframe of this study (6.45am$3.15 \mathrm{pm})$. This was a limitation of the study.

The availability of a signal in the EHR system to alert, notify or prompt the nursing staff of changes in conditions for older people would enhance collaboration of nursing staff in their care duty. ${ }^{21}$ However, the EHR system at the 
nursing home only functioned as a repository of information instead of being a facilitator to support collaborative nursing care. This is a design limitation that can be improved so as to substantially improve the support by technology of social work in nursing care practice.

After 23 months of using the EHR system, RNs spent significantly more time on nursing documentation; this appeared to be offset by a significant drop in the proportion of time they spent on oral communication. This finding may suggest that RNs had become more fluent in electronic communication, including locating the information needed to complete their documentation activity. As such, they relied less on sharing or obtaining information orally.

The PCs' proportion of time on communication declined and the proportion on documentation increased at almost all periods in 12 months after the introduction of the EHR system. This may be associated with the cognitive design of the EHR system. The system did not adequately support the PCs' communication and information needs for cognition. ${ }^{22}$ In the first 12 months, the system changed the way the PCs communicated and documented their care work. They spent less time interacting with each other and with their supervisors (RNs and EENs) to share or obtain care information. Instead, they spent more time on documentation for these purposes.

At 23 months, however, the proportion of their time on these activities had settled back to the original level evident in the paper-based system. This suggests that ultimately PCs' preferred oral communication to obtain or share care information. The reason might be that oral communication was easier for cognition. ${ }^{23}$ Our informal discussion with nursing staff suggested that PCs needed to be continuously educated so as to understand the importance of documentation for communication amongst themselves and with their supervisors. Design of an EHR system that fits with the practices of PCs in information acquisition, sharing, and cognition remains an unresolved challenge for automating records in nursing homes.

Nursing home leaders are concerned that nursing staff may take a long time to learn how to use an EHR system, a situation that might interfere with their duties of caring for older people. ${ }^{10}$ In this study, however, the proportion of time nursing staff spent on direct care or medication management remained unchanged at all periods after system implementation. This finding suggests that the introduction of an EHR system may not necessarily interfere with the caring duty of the nursing staff. This positive result may be explained by the nursing staff's clear understanding of their role as primary care providers. ${ }^{24}$ They often prioritise their primary duty of caring for the older people above any other duty. This is evident in their documentation practice at the nursing home. They always performed their documentation at the end of a work shift, instead of documenting their care in real time. This practice may be a result of the current EHR system, which is either desktop computer-based or laptop based; these formats are unable to adequately support point-of-care documentation. Therefore, another area for improvement of the EHR system is to support documentation at the point of care. A possibility is the integration of mobile devices that nursing staff can carry around and perform their documentation or build audio recording functions into the devices to support this activity.

The results of the study, however, must be interpreted with caution. First, this investigation was conducted in a single nursing home with a particular organisational structure. The PCs and EENs reported to the RNs, and the RNs reported directly to the residential service manager. The nursing home also had a particular culture and task allocation for each type of nursing staff. In addition, the EHR system used at the home was a commercial system with certain functions and documentation workflow. As many components of nursing records were still documented on paper, this added the burden for record management. However, Zhang et al. suggest that if all nursing information were being documented in the EHR system, the amount of time the nursing staff spent on documentation would have decreased. ${ }^{25}$ Therefore; the findings of this study may not be fully generalisable to other nursing homes using other types of EHR systems.

The study was focused on nursing staff working on a morning shift. It is unknown whether the results from this shift correctly reflect nursing staff's practice in the afternoon and night shifts. In addition, the activity categories with a small sample size were excluded from the analysis and, possibly, their inclusion might have had an effect on the results.

This study had no control group and hence, it is impossible to ascertain whether the changes in proportion of time on activities after implementation were directly attributed to the newly introduced EHR system. To our knowledge, however, there were no internal or external factors causing obvious change in record management.

The study also focused on changes in nursing staff time and did not explore the changes in detail for each activity after the implementation of the EHR system. A comprehensive analysis on how the activity changes due to the EHR system implementation has been reported elsewhere. $^{26}$

This investigation used a work sampling technique. The method is useful in evaluating care practice and time on 
activities in healthcare. For example, it allows many observations to be recorded in a short period, thus increasing the representativeness of data obtained. However, time obtained is an estimate and not the real time needed to complete an activity. Our study had a large sample size, thus, we consider our estimate of time on activities before and after the implementation of the EHR system to represent the time nursing staff spent on activities at the nursing home.

\section{Conclusion}

Our results suggest that the successful introduction of an EHR system in a nursing home may not require nursing staff to sacrifice their time with residents. This may help to allay fears of the nursing home leaders and motivate them to introduce EHR systems into nursing practice.

However, the introduction of an EHR system in a nursing home may not change the PCs' behaviour of communication. Therefore, although the use of an EHR system may stimulate a positive change in documentation practice in a nursing home, maintaining this positive change may be achallenge.

Given that documentation is an important collaborative activity in a nursing home, it is important for designers of EHR systems to recognise this and incorporate the necessary features into the system to support the nursing staff in caring for the older people.

Future research may need to use a control group and employ time and motion study techniques to assess the exact work practice and duration of each activity of nursing staff. Findings from such studies may be compared with the findings of our study to ascertain the nature of nursing care work in nursing homes, and the extent to which results from the two study methods are similar or different. This information is not only useful for measuring the work practice of nursing staff, but also for measuring the impact of any practice change initiatives in nursing homes.

\section{References}

1. Institute of Medicine. Keeping Patients Safe: Transforming the Work Environment of Nurses. Washington DC: National Academies Press; 2004.

2. Munyisia EN, $\mathrm{Yu} P$, Hailey $D$. The changes in caregivers' perceptions about the quality of information and benefits of nursing documentation associated with the introduction of an electronic documentation system in a nursing home. Int J Med Inform. 2011a; 80:116-26.

3. Ball MJ, Weaver C, Abbott PA. Enabling technologies promise to revitalize the role of nursing in an era of patient safety. Int J Med Inform. 2003;69:29-38.

4. Bosman RJ, Rood E, Oudemans-van Straaten HM, Van der Spoel JI, Wester JP, Zandstra DF. Intensive care information system reduces documentation time of the nurses after cardiothoracic surgery. Intensive Care Med. 2003;29:83-90.

5. Hakes B, Whittington J. Assessing the impact of an electronic medical record on nurse documentation time. Comput Inform Nurs. 2008;26:234-41.

6. Gabr $\mathrm{H}$. The effect of computerized patient record on nurses' time spend on documentation in inpatient units. Int J Acad Res. 2010;2:108-20.

7. Wong DH, Gallegos Y, Weinger MB, Clack S, Slagle $\mathrm{J}$, Anderson CT. Changes in intensive care unit nurse task activity after installation of a third-generation intensive care unit information system. Crit Care Med. 2003;31:2488-94.

8. Munyisia EN, Yu P, Hailey D. Does the introduction of an electronic nursing documentation system in a nursing home reduce time on documentation for the nursing staff? Int J Med Inform. 2011b;80:782-92.

9. Cherry JC, Ford WF, Peterson LT. Experiences with electronic health records: early adopters in long-term care facilities. Health Care Manag Rev. 2011; 36:26574.

10. Cherry B, Carter M, Owen D, Lockhart C. Factors affecting electronic health record adoption in longterm care facilities. J healthc Qual. 2008;30:37-47.

11. Productivity Commission. Caring for older Australians: draft report. Canberra: Commonwealth of Australia; 2011.

12. Munyisia EN, Yu P, Hailey D. The impact of an electronic nursing documentation system on efficiency of documentation by caregivers in a residential aged care facility. J Clin Nurs. 2012;21:2940-8.

13. Australian Nursing Federation \& Royal College of Nursing. Joint position statement: assistants in nursing and other unlicensed workers [Internet]. 2008 [cited 2014 March 31]. Available from: http://anmf.org.au/documents/policies/RCNA_JPS_

14. Gibson T, Heartfield M. Australian enrolled nurses have their say-part 2: scope of practice. Contemp Nurse. 2005;19:126-136.

15. Australian Nursing and Midwifery Council: National Competency Standards for the Registered Nurse [internet]. 2005 [cited 2014 March 31]. Available from:

http://theses.flinders.edu.au/uploads/approved/adtSFU20100708.110421/public/09Appendix7.pdf.

16. Martin B, King D. Who cares for older Australians? A picture of the residential and community based aged care workforce, 2007. Canberra: Commonwealth of Australia; 2008.

17. Talmon J, Enning J, Castaneda G, Eurlings F, Hoyer D, NykanenP, Sanz F, Thayer C, Vissers M. The VATAM guidelines. Int J Med Inform. 1999;56:107-115. 
18. Pelletier D, Duffield C. Work sampling: valuable methodology to define nursing practice patterns. Nurs Health Sci. 2003;5:31-8.

19. Munyisia E, Yu P, Hailey D. Development and testing of a work measurement tool to assess caregivers' activities in residential aged care facilities. In: Safran C, editor. MEDINFO 10. Proceedings of the 13th World Congress on Medical Informatics; 2010 Sep 12-15; Cape town, South Africa. Amsterdam: IOS Press; 2010. P.1226-30.

20. Reddy M, Pratt W, Dourish P, Shabot MM. Sociotechnical requirements analysis for clinical systems. Methods Inf Med. 2003; 42:437-44.

21. Bowers JM, Benford S, editors. Studies in computer supported cooperative work: theory, practice, and design. New York: Eslevier Science Pub.Co; 1991.

22. Carayon P, Bass E, Bellandi T, Gurses A, Hallbeck S, Mollo V. Socio-technical anaysis in healthcare: a research agenda. IIE Trans Healthc Syst Eng. 2011; 1:145-160.

23. Coiera $E$. When conversation is better than computation. JAMA 2000; 7: 277-286.

24. Crofton C, Witney G, editors. Nursing documentation and aged care: a guide to practice. Melbourne: Ausmed Publications; 2004.

25. Zhang $Y, Y u$, Shen J. The benefits of introducing electronic health rcords in residential aged care facilities: a multiple case study. Int J Med Inform. 2012;81:690-704.

26. Wang N, Yu P, Hailey D. Description and comparison of quality of electronic versus paper-based resident admission forms in Australian aged care facilites. Int J Med Inform. 2013; 82:313-24.

\section{ACKNOWLEDGEMENTS}

The authors would like to thank the following: the Registered Nurses, Endorsed Enrolled Nurses and Personal Carers at Albion Park Rail nursing home for their consent to participate in this study; the managers of Warrigal Care Aged Care Organization including the CEO Mark Sewell, Care Systems Officer Dylan Hepworth, Research Officer Renshaw Shandell and the Residential Service Manager Helen Pavlik for providing the necessary support needed to complete the study.

\section{PEER REVIEW}

Not commissioned. Externally peer reviewed.

\section{CONFLICTS OF INTEREST}

The authors declare that they have no competing interests.

\section{FUNDING}

The project was funded by the Australian Research Council Industry Linkage Grant Scheme, Project No. LP0882430.

\section{ETHICS COMMITTEE APPROVAL}

Human Research Ethics Committee of the University of Wollongong, Australia. Reference No: HE08/263. 
Table 1: The five data collection periods

\begin{tabular}{|l|l|l|}
\hline \multicolumn{2}{|c|}{ Measurement time } & Month/Year \\
\hline $1^{\text {st }}$ period & 2 months prior to EHR introduction & March 2009 \\
\hline Intervention & Implementation of the EHR system & May-June 2009 \\
\hline $2^{\text {nd }}$ period & 3 months after EHR introduction & August 2009 \\
\hline $3^{\text {rd }}$ period & 6 months after EHR introduction & November 2009 \\
\hline $4^{\text {th }}$ period & 12 months after EHR introduction & May 2010 \\
\hline $5^{\text {th }}$ period & 23 months after EHR introduction & April 2011 \\
\hline
\end{tabular}

Table 2: The RNs' proportion of time on activities before and after the implementation of the EHR system

\begin{tabular}{|c|c|c|c|c|c|}
\hline \multirow[b]{2}{*}{ Activity categories } & \multicolumn{5}{|c|}{$\%$ (number of observations) } \\
\hline & $\begin{array}{c}2 \text { months } \\
\text { before } \\
n=430\end{array}$ & $\begin{array}{c}3 \text { months } \\
\text { after } \\
n=448\end{array}$ & $\begin{array}{c}6 \text { months } \\
\text { after } \\
n=333\end{array}$ & $\begin{array}{c}12 \text { months } \\
\text { after } \\
n=454\end{array}$ & $\begin{array}{c}23 \text { months } \\
\text { after } \\
n=260\end{array}$ \\
\hline Oral Communication & $48.4^{a}+(208)$ & $47.8^{\mathrm{a}}(214)$ & $43.5^{\mathrm{a}}(145)$ & $49.8^{\mathrm{a}}(228)$ & $36.2^{\mathrm{b}}(94)$ \\
\hline Documentation & $17.7^{\mathrm{a}}(76)$ & $15.6^{\mathrm{a}}(70)$ & $22.8^{\mathrm{a}}(76)$ & $13.7^{\mathrm{a}}(62)$ & $28.5^{\mathrm{b}}(74)$ \\
\hline Direct Care & $7.7^{\mathrm{a}}(33)$ & $5.6^{a}(25)$ & $4.8^{\mathrm{a}}(16)$ & $4.2^{a}(19)$ & $10.4^{\mathrm{a}}(27)$ \\
\hline $\begin{array}{l}\text { Medication } \\
\text { management }\end{array}$ & $18.1^{\mathrm{a}}(78)$ & $23.0^{\mathrm{a}}(103)$ & $19.8^{\mathrm{a}}(66)$ & $22.5^{\mathrm{a}}(102)$ & $18.1^{\mathrm{a}}(47)$ \\
\hline Personal & $5.1^{\mathrm{a}}(22)$ & $4.7^{\mathrm{a}}(21)$ & $4.5^{\mathrm{a}}(15)$ & $4.8^{\mathrm{a}}(22)$ & $3.1^{\mathrm{a}}(8)$ \\
\hline In-transit & $3.0^{\mathrm{a}}(13)$ & $3.3^{\mathrm{a}}(15)$ & $4.5^{\mathrm{a}}(15)$ & $4.6^{\mathrm{a}}(21)$ & $3.8^{\mathrm{a}}(10)$ \\
\hline
\end{tabular}

tThe same superscript letter before and after the implementation of the EHR system represents no significant change in the proportion of time spent on an activity. Different superscript letters before and after implementation denote a significant change in the proportion of time on the activity. A significance level of 0.002 was considered statistically significant.

$n=$ Total observations

Table 3: The EENs' proportion of time on activities before and after the implementation of the EHR system

\begin{tabular}{|l|c|c|c|c|c|}
\hline & \multicolumn{5}{|c|}{$\%$ (number of observations) } \\
\cline { 2 - 6 } Activity categories & $\begin{array}{c}2 \text { months before } \\
n=313\end{array}$ & $\begin{array}{c}3 \text { months after } \\
n=247\end{array}$ & $\begin{array}{c}6 \text { months after } \\
n=298\end{array}$ & $\begin{array}{c}12 \text { months after } \\
n=187\end{array}$ & $\begin{array}{c}23 \text { months } \\
\text { after } \\
n=339\end{array}$ \\
\hline Oral Communication & $39.3^{\mathrm{a}}+(123)$ & $44.5^{\mathrm{a}}(110)$ & $34.9^{\mathrm{a}}(104)$ & $43.3^{\mathrm{a}}(81)$ & $49.3^{\mathrm{a}}(167)$ \\
\hline Documentation & $30.7^{\mathrm{a}}(96)$ & $24.3^{\mathrm{a}}(60)$ & $30.2^{\mathrm{a}}(90)$ & $18.7^{\mathrm{b}}(35)$ & $19.2^{\mathrm{b}}(65)$ \\
\hline $\begin{array}{l}\text { Medication } \\
\text { management }\end{array}$ & $18.8^{\mathrm{a}}(59)$ & $23.5^{\mathrm{a}}(58)$ & $24.8^{\mathrm{a}}(74)$ & $25.7^{\mathrm{a}}(48)$ & $25.1^{\mathrm{a}}(85)$ \\
\hline Personal & $8.3^{\mathrm{a}}(26)$ & $4.0^{\mathrm{a}}(10)$ & $5.0^{\mathrm{a}}(15)$ & $7.5^{\mathrm{a}}(14)$ & $3.8^{\mathrm{a}}(13)$ \\
\hline In-transit & $2.9^{\mathrm{a}}(9)$ & $3.6^{\mathrm{a}}(9)$ & $5.0^{\mathrm{a}}(15)$ & $4.8^{\mathrm{a}}(9)$ & $2.7^{\mathrm{a}}(9)$ \\
\hline
\end{tabular}

tThe same explanation of superscripts as in Table 2. A significance level of 0.003 was considered statistically significant. $n=$ Total observations 
Table 4: The PCs' proportion of time on activities before and after the implementation of the EHR system

\begin{tabular}{|l|l|l|l|l|l|}
\hline \multirow{2}{*}{ Activity categories } & \multicolumn{1}{|c}{$\%$ (number of observations) } \\
\cline { 2 - 6 } & $\begin{array}{c}\text { 2 months } \\
\text { before } \\
n=2,723\end{array}$ & $\begin{array}{c}3 \text { months } \\
\text { after } \\
n=3,126\end{array}$ & $\begin{array}{c}6 \text { months after } \\
n=3,076\end{array}$ & $\begin{array}{c}12 \text { months } \\
\text { after } \\
n=2,745\end{array}$ & $\begin{array}{c}23 \text { months } \\
\text { after } \\
n=2,753\end{array}$ \\
\hline Oral communication & $34.4^{\mathrm{a}}+(938)$ & $28.3^{\mathrm{b}}(885)$ & $30.3 \mathrm{~b}(932)$ & $29.5^{\mathrm{b}}(809)$ & $32.8^{\mathrm{a}}(904)$ \\
\hline Documentation & $6.5^{\mathrm{a}}(177)$ & $10.5^{\mathrm{b}}(329)$ & $9.7^{\mathrm{b}}(298)$ & $7.9^{\mathrm{a}}(218)$ & $7.5^{\mathrm{a}}(206)$ \\
\hline Direct care & $40.3^{\mathrm{a}}(1097)$ & $41.9^{\mathrm{a}}(1310)$ & $38.1^{\mathrm{a}}(1171)$ & $39.4^{\mathrm{a}}(1081)$ & $41.0^{\mathrm{a}}(1130)$ \\
\hline Personal & $5.0^{\mathrm{a}}(136)$ & $5.5^{\mathrm{a}}(173)$ & $4.9^{\mathrm{a}}(151)$ & $8.2^{\mathrm{b}}(225)$ & $4.1^{\mathrm{a}}(113)$ \\
\hline In-transit & $4.8^{\mathrm{a}}(131)$ & $4.4^{\mathrm{a}}(136)$ & $7.5^{\mathrm{b}}(230)$ & $5.2^{\mathrm{a}}(143)$ & $5.0^{\mathrm{a}}(137)$ \\
\hline Indirect care & $9.0^{\mathrm{a}}(244)$ & $9.4^{\mathrm{a}}(293)$ & $9.6^{\mathrm{a}}(294)$ & $9.8^{\mathrm{a}}(269)$ & $9.6^{\mathrm{a}}(263)$ \\
\hline
\end{tabular}

+ The same explanation of superscripts as in Table 2. A significance level of 0.002 was considered statistically significant.

$n=$ Total observations 